\title{
ADUBAÇÃO ORGÂNICA E FERTIRRIGAÇÃO POTÁSSICA EM VIDEIRA 'SYRAH' NO SEMIÁRIDO
}

\section{DAVI JOSÉ SILVA ${ }^{1}$; ALEXSANDRO OLIVEIRA DA SILVA ${ }^{2}$; LUÍS HENRIQUE BASSOI ; BRUNO RICARDO SILVA COSTA $^{3}$; RAFAEL POMBO TEIXEIRA ${ }^{2}$ E DIOGO RONIELSON MARINHO DE SOUZA ${ }^{4}$}

\footnotetext{
${ }^{1}$ Engenheiro Agrônomo, Pesquisador da Embrapa Semiárido, davi.jose@embrapa.br; luis.bassoi@embrapa.br ${ }^{2}$ Engenheiro Agrônomo, Doutorando em Irrigação e Drenagem, Faculdade de Ciências Agronomicas, Universidade Estadual Paulista, alexsandro_oliveira01@hotmail.com, rafael.ufla@hotmail.com

${ }^{3}$ Tecnólogo em Fruticultura Irrigada, Mestrando em Engenharia Agrícola, Universidade Federal do Vale do São Francisco, bruno.ricardo.silva@hotmail.com

${ }^{4}$ Graduando em Ciências Biológicas, Bolsista de Iniciação Científica do CNPq, Universidade de Pernambuco, Campus Petrolina, diogoronielson@hotmail.com
}

\section{RESUMO}

Apesar da grande importância da adubação na qualidade das uvas, ainda existem poucos estudos sobre a fertirrigação em videira de vinho no Vale do Submédio São Francisco. Com o objetivo de avaliar a produção de uvas sob a influência de doses de potássio e de adubo orgânico, um experimento foi realizado na Embrapa Semiárido, em Petrolina-PE, com videiras (Vitis vinifera L.), 'Syrah', enxertadas sobre o porta-enxerto 'Paulsen' 1103 e cultivadas no espaçamento $3 \mathrm{x} 1 \mathrm{~m}$. As plantas foram irrigadas por um sistema de gotejamento, com um emissor por planta, com vazão de $2 \mathrm{~L} \mathrm{~h}^{-1}$. Os tratamentos foram constituídos de cinco doses de potássio $\left(0,20,40,80\right.$ e $\left.160 \mathrm{~kg} \mathrm{ha}^{-1}\right)$ e duas doses de adubo orgânico $\left(0 \mathrm{e} 7,5 \mathrm{~m}^{3} \mathrm{ha}^{-1}\right)$. Estes tratamentos foram dispostos em parcelas subdivididas no qual o adubo orgânico constituiu as parcelas e as doses de potássio as subparcelas. Foram avaliados na colheita o número de cachos por planta, a produção total por planta, o peso médio dos cachos e o rendimento total das plantas. As diferentes doses de potássio aplicadas pelo sistema de irrigação e de adubo orgânico aplicados via solo não influenciaram significativamente as características avaliadas.

Palavras-chave: Vitis vinifera L., irrigação, fertilizante.

\section{INTRODUÇÃO}

A vitivinicultura é uma das atividades agrícolas de grande importância para o Vale do Submédio São Francisco. A produção de vinho é responsável pela geração de renda e emprega direta e indiretamente em torno de três mil pessoas. Esta produção representa 15\% do mercado nacional de vinhos de mesa finos, sendo ainda exportada para outros países (Instituto do Vinho do Vale do São Francisco, 2008).

A adubação orgânica exerce um papel essencial na cultura da videira. Os solos da região semiárida apresentam, via de regra, baixos teores de matéria orgânica. A adição de adubos orgânicos como, estercos e compostos, é essencial para incrementar os teores de matéria orgânica desses solos. Bustamante et al. (2011) avaliaram, durante três safras, os efeitos da aplicação de diferentes compostos derivados de resíduos de vinificação e de esterco de ovinos em um solo calcário cultivado com videiras 'Monastrell'. Os autores observaram que os compostos aumentaram a concentração de $\mathrm{N}$ orgânico no solo. Além disso, a aplicação do material orgânico induziu o aumento da atividade microbiana no solo e os teores de macro e 
micronutrientes, assim como a liberação de $\mathrm{N}$ inorgânico. Efeitos positivos da adubação orgânica também foram reportados para outras frutíferas como nectarineiras (BALDI et al. 2010; TOSELLI, 2010) e mangueiras (SILVA et al., 2013).

O manejo de irrigação é um dos fatores que mais influenciam no equilíbrio vegetativo e reprodutivo da videira. De acordo com Bassoi et al. (2007), o equilíbrio entre o desenvolvimento vegetativo e reprodutivo é uma prática importante para a obtenção da qualidade desejável da uva de vinho e o controle da água é um instrumento importante para alcançar este equilíbrio, principalmente em vinhedos irrigados, como nos pomares do Vale do Submédio São Francisco. Estes autores avaliaram estratégias de irrigação (com déficit controlado e secamento parcial do sistema radicular) em videiras 'Syrah' enxertadas sobre os porta-enxertos 'IAC 572' e '1103 P'. As estratégias não afetaram a produção, o comportamento fisiológico e o crescimento das plantas.

A fertirrigação consiste na técnica que utiliza o sistema de irrigação como condutor e distribuidor de fertilizantes. Para garantir a eficiência da fertirrigação é necessário levar em consideração as características técnicas de concepção e manutenção do sistema de irrigação e dimensionamento e monitoramento das necessidades hídricas em cada fase fenológica da videira (SILVA \& SOARES, 2009). Dessa forma, o manejo de irrigação e de fertirrigação, realizado de acordo com as características do fertilizante, condições de solo, características climáticas, e demanda da cultura, deve proporcionar o fornecimento de água e nutrientes ajustado às necessidades da videira, contribuindo ainda para maior eficiência de uso da água e dos fertilizantes.

O potássio é o nutriente exportado em maior quantidade pela videira (TERRA 2003; ALBUQUERQUE et al., 2005). A sua importância está relacionada a manutenção da quantidade de água nas plantas, exercendo ainda importantes funções na fisiologia da planta como, ativação de enzimas, regulação da turgidez do tecido, abertura e fechamento dos estômatos, no controle da concentração de $\mathrm{CO}_{2}$ na câmara sub-estomática, na realização da fotossíntese, na translocação de carboidratos, na síntese de proteínas, além de reduzir os danos causados por geadas, seca e por salinidade (HAWKESFORD et al., 2012).

Existem vários fertilizantes contendo compostos potássicos que podem ser usados na fertirrigação da videira, como cloreto, nitrato e sulfato de potássio (BORGES \& SILVA, 2011).

Em vinhedos de 'Niagara Rosada' enxertada sobre o porta-enxerto IAC 766, a produtividade correlacionou-se positivamente com os teores de potássio no solo, a relação $\mathrm{K} / \mathrm{Mg}$ nas folhas e os teores de potássio nas folhas; houve correlação negativa entre produtividade com a relação $(\mathrm{Ca}+\mathrm{Mg}) / \mathrm{K}$ no solo e os teores de cálcio e magnésio nas folhas, exibindo o antagonismo entre o magnésio e o potássio (TECCHIO et al., 2006). Em outro trabalho realizado em 93 vinhedos de três regiões vitícolas do Estado de São Paulo (Jundiaí, São Miguel Arcanjo e Jales), Tecchio et al. (2011) compararam os teores de nutrientes em amostras foliares e o teor de nitrato e de potássio na seiva do pecíolo da videira 'Niagara Rosada', observando que os teores desses nutrientes variam entre as regiões vitícolas. As concentrações de nitrato e de potássio na seiva do pecíolo e os teores de potássio nas folhas foram menores em Saõ Miguel Arcanjo, possivelmente pela interferência do cálcio, pois naquela região os solos apresentaram teores deste nutriente duas vezes maiores que nas demais, embora os autores atribuam esta diferença aos porta-enxertos utilizados em cada região do estudo.

O potássio tem uma grande importância na enologia, pois exerce influência sobre o $\mathrm{pH}$ dos vinhos. Os valores de $\mathrm{pH}$ recomendados para a manutenção da estabilidade química e sensorial dos vinhos estão entre 3,2 e 3,4 para brancos e 3,3 e 3,6 para tintos. Em condições de alta concentração de potássio, os valores no mosto e no vinho podem requer quantidades elevadas de $\mathrm{SO}_{2}$ livre ou $\mathrm{SO}_{2}$ ativo, que será adicionado ao vinho durante o processo de 
vinificação, podendo causar problemas de aromas indesejáveis (PEYNAUD, 1997; REYNIER, 2007). Durante a fase de amadurecimento das bagas de videiras Pinot Noir, Cabernet Sauvignon e Merlot, Fogaça et al. (2007) observaram que o aumento nos teores de potássio absorvidos pelos frutos foi acompanhado pela elevação do $\mathrm{pH}$. A retirada de amostras peciolares na floração e trinta dias depois mostrou-se um mecanismo eficiente na avaliação do teor de potássio nos tecidos próximos as bagas.

Alguns solos do Vale do Submédio São Francisco apresentam elevados teores naturais de potássio, fato relacionado ao material de origem e processos de pedogênese (CUNHA et al., 2010). Como existem poucos estudos sobre respostas da videira a fertilizantes potássicos na região, principalmente quando estes envolvem a técnica da fertirrigação, pesquisas sobre o tema são importantes para estabelecer limites de adubação que proporcionem ganhos de produção e de qualidade das uvas e dos vinhos.

Este trabalho tem como objetivo avaliar a produção da uva de vinho cv. Syrah quando submetida a adubação orgânica e diferentes dosagens de potássio via fertirrigação durante o ciclo de produção no Semiárido pernambucano.

\section{MATERIAL E MÉTODOS}

O experimento foi instalado no Campo Experimental de Bebedouro (latitude $9^{\circ} 8^{\prime}$ 8,9" S, longitude $40^{\circ} 18^{\prime} 33,6^{\prime \prime}$ O, altitude 373 m) pertencente a Embrapa Semiárido em PetrolinaPE. A videira (Vitis vinifera L.) cultivar Syrah foi enxertada sobre o porta enxerto Paulsen 1103. O plantio no campo foi realizado em 30 de abril de 2009 , no espaçamento de $1 \mathrm{~m}$ entre plantas e $3 \mathrm{~m}$ entre fileiras e a condução feita no sistema de espaldeira. O solo da área foi classificado como Argissolo Vermelho Amarelo Eutrófico Latossólico, textura média (SILVA, 2005), apresentando na camada de 0 a $0,2 \mathrm{~m}$ de profundidade, $81 \mathrm{~g} \mathrm{~kg}^{-1}$ de areia, 13 $\mathrm{g} \mathrm{kg}^{-1}$ de silte e $6 \mathrm{~g} \mathrm{~kg}^{-1}$ de argila. Amostras de solo coletadas antes do plantio das mudas de videira apresentaram a seguinte composição química: $\mathrm{pH}-\mathrm{H}_{2} \mathrm{O} 6,7, \mathrm{CE} 0,46 \mathrm{dS} \mathrm{m}^{-1}$, matéria orgância (MO) 10,4 $\mathrm{g} \mathrm{dm}^{-3}, \mathrm{P} \mathrm{88,8} \mathrm{mg} \mathrm{dm}^{-3}, \mathrm{~K} \mathrm{3,8}$ mmol $_{\mathrm{c}} \mathrm{dm}^{-3}$, Ca 25,4 $\mathrm{mmol}_{\mathrm{c}} \mathrm{dm}^{-3}$, Na 0,3 $\mathrm{mmol}_{\mathrm{c}} \mathrm{dm}^{-3}$, CTC 49,2 $\mathrm{mmol}_{\mathrm{c}} \mathrm{dm}^{-3}$, V $81 \%$.

Os tratamentos foram constituídos de duas doses de adubo orgânico $\left(0\right.$ e 7,5 $\left.\mathrm{m}^{3} \mathrm{ha}^{-1}\right)$ e cinco doses de potássio $\left(0,20,40,80\right.$ e $\left.160 \mathrm{~kg} \mathrm{ha}^{-1}\right)$. Estes tratamentos foram dispostos em parcelas subdivididas. $\mathrm{O}$ adubo orgânico constituiu as parcelas e as doses de potássio as subparcelas. A unidade experimental foi constituída de 16 plantas, sendo 8 plantas úteis. $\mathrm{O}$ delineamento experimental adotado foi de blocos casualizados com cinco repetições. A adubação orgânica foi realizada previamente antes da poda de produção, com esterco de

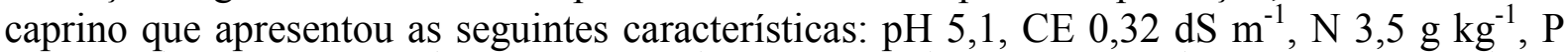
$2,2 \mathrm{~g} \mathrm{~kg}^{-1}, \mathrm{Ca} 13,1 \mathrm{~g} \mathrm{~kg}^{-1}, \mathrm{Mg} 4,7 \mathrm{~g} \mathrm{~kg}^{-1}, \mathrm{~S} 2,3 \mathrm{~g} \mathrm{~kg}^{-1}$, B 37,3 $\mathrm{g} \mathrm{kg}^{-1}, \mathrm{Cu} 21,1 \mathrm{mg} \mathrm{kg}^{-1}, \mathrm{Fe}$ $4495 \mathrm{mg} \mathrm{kg}^{-1}$, Mn 338,7 $\mathrm{mg} \mathrm{kg}^{-1}$, Zn 55,2 $\mathrm{mg} \mathrm{kg}^{-1}$ e Na $1482,7 \mathrm{mg} \mathrm{kg}^{-1}$.

A irrigação foi realizada em sistema de gotejamento, com emissores espaçados em 0,5 $\mathrm{m}$ na linha, com vazão de $2 \mathrm{~L} \mathrm{~h}^{-1}$. A adubação potássica foi realizada por meio da fertirrigação, com o auxílio de uma bomba injetora elétrica, durante o ciclo compreendido entre 29/04/13 (poda de produção) e 23/08/13 (colheita). Os fertilizantes foram aplicados semanalmente, por em um período de 10 semanas, com $40 \%$ das doses aplicadas nas primeiras quatro semanas (antes do florescimento) e 60\% nas seis semanas seguintes (após o florescimento). As fontes de potássio utilizadas foram sulfato de potássio, nitrato de potássio e cloreto de potássio.

O manejo da irrigação foi realizado com base na evapotranspiração da cultura (ETc, $\mathrm{mm}$ ), estimada pelo produto entre a evapotranspiração de referência (ETo, mm), determinada pelo método de Penman-Monteith FAO (ALLEN et al., 1998) com parâmetros medidos por 
estação agrometeorológica automática instalada a cerca de $60 \mathrm{~m}$ da área do experimento, e os coeficiente de cultura (Kc) recomendados por Bassoi et al. (2007), determinados na mesma área do experimento (poda até o ínicio da brotação: 0,7; início do florescimento: 1,0; frutificação: 1,0 ; cacho formado: 0,8 ; maturação: 0,5 ).

O potencial matricial da água no solo foi determinado por tensiômetros de punção a $0,20,0,40,0,60$ e $0,80 \mathrm{~m}$ de profundidade, e os respectivos valores de umidade do solo foram determinados por meio de curva de retenção de água no solo. utilizando-se o modelo de van Genuchten (1980) para a sua determinação. Os parâmetros empíricos foram estimados com o software Curvaret (DOURADO NETO \& VAN LIER, 1993) conforme Tabela1.

Tabela 1. Parâmetros da equação da curva de retenção de água no solo

\begin{tabular}{cccccc} 
Prof $(\mathrm{m})$ & $\alpha$ & $\mathrm{m}$ & $\mathrm{n}$ & $\theta \mathrm{r}\left(\mathrm{cm}^{3} \mathrm{~cm}^{-3}\right)$ & $\theta \mathrm{s}\left(\mathrm{cm}^{3} \mathrm{~cm}^{-3}\right)$ \\
\hline 0,2 & 0,3315 & 0,3298 & 1,4921 & 0,082 & 0,599 \\
0,4 & 0,1507 & 0,3724 & 1,5933 & 0,116 & 0,596 \\
0,6 & 0,3692 & 0,3238 & 1,4888 & 0,103 & 0,638 \\
0,8 & 0,5094 & 0,3125 & 1,4545 & 0,107 & 0,642 \\
1,0 & 0,1303 & 0,4063 & 1,6842 & 0,114 & 0,612 \\
\hline
\end{tabular}

$\theta \mathrm{r}=$ umidade residual, $\theta \mathrm{s}=$ umidade de saturação, $\alpha, \mathrm{m}$ e $\mathrm{n}=$ parâmetros de ajuste que dependem do solo

Entre 30/05 e 16/08/13 (33 a 111 dapp) foi realizada a extração da solução do solo utilizando-se 30 extratores de cápsulas porosas, instalados na área experimental nas profundidades de 0,40 e 0,60 m, distanciados em 0,10 $\mathrm{m}$ dos emissores e a 0,30 $\mathrm{m}$ da planta. O extrator de solução do solo foi composto de tubo de PVC, conectado na extremidade inferior a uma cápsula de cerâmica porosa. $\mathrm{Na}$ extremidade superior o extrator foi vedado com rolha, e por esta passavam dois tubos de naylon, em um deles se aplicava o vácuo e no outro ficava conectado uma seringa por onde se coletava a solução. Após cada evento de fertirrigação, com o auxílio de uma bomba de vácuo manual os extratores eram submetidos a uma aplicação de vácuo com tensão de $60 \mathrm{kPa}$. Um dia após esta aplicação, as soluções do solo eram coletadas e levadas para o Laboratório de Análise de Solo e Planta da Embrapa Semiárido onde foram determinadas as concentrações de potássio $\left(\mathrm{K}, \mathrm{mg} \mathrm{L}^{-1}\right)$ por fotometria de chama. Foram realizadas 11 coletas de solução do solo ao longo do experimento (uma coleta por semana).

Por ocasião da colheita (116 dias após a poda de produção - dapp), foi determinado o número de cachos (NC) e a produção total por planta (PTP). A partir desses dados foram estimados o peso médio dos cachos (PMC) e o rendimento total (RT, $\left.\mathrm{kg} \mathrm{ha}^{-1}\right)$. Os dados foram submetidos à análise de variância, sendo o fator adubo orgânico avaliado pelo teste $\mathrm{F}$ a $5 \%$ de probabilidade e o fator adubo potássico submetido à análise de regressão.

\section{RESULTADOS E DISCUSSÃO}

Durante o ciclo de produção, houve uma precipitação total de $25 \mathrm{~mm}$, enquanto que a ETc foi de 464,35 mm (Tabela 3). Os maiores valores de ETc foram observados no período compreendido entre 11 e 35 dapp totalizando 139,41 $\mathrm{mm}$. Em estudos sobre deficit hídrico nas condições de Petrolina-PE, Bassoi et al. (2007) observaram uma ETc com valor de 425,7 $\mathrm{mm}$ ciclo $^{-1}$, valor este inferior ao observado neste estudo, possivelmente as condições climáticas nas diferentes épocas (2004 e 2013) em que os experimentos foram conduzidos, podem explicar o aumento do consumo de água pelas plantas. 
Tabela 2. Manejo da irrigação durante o ciclo produtivo da videira 'Syrah' em Petrolina-PE no período de 29/04 a 23/08/13

\begin{tabular}{ccccc}
\hline dapp & ETo & ETc & P & LI \\
\hline 0 a 10 & 47,41 & 33,98 & 7,6 & 33,93 \\
11 a 35 & 131,26 & 125,47 & 0 & 139,41 \\
36 a 55 & 96,04 & 76,83 & 4,4 & 87,71 \\
56 a 80 & 132,22 & 105,78 & 7,5 & 113,31 \\
80 a 116 & 217,15 & 122,27 & 5,5 & 132,81 \\
\hline Total & 624,10 & 464,35 & 25 & 507,17 \\
\hline
\end{tabular}

dapp $=$ dias após a poda de produção; ETo=evapotranspiração de referência $(\mathrm{mm}) ; \mathrm{ETc}=$ evapotranspiração da cultura $(\mathrm{mm}) ; \mathrm{P}=$ precipitação $(\mathrm{mm}) ; \mathrm{LI}=$ lâmina de irrigação $(\mathrm{mm})$

A umidade do solo (Figura 1) apresentou valores entre 0,35 a $0,21 \mathrm{~m}^{3} \mathrm{~m}^{-3}$, durante todo o ciclo de cultivo, sempre próximas a capacidade campo, o que facilita a absorção da solução do solo pela cultura. Segundo Pires et al. (2003) o sistema de irrigação localizada permite uma alta frequência de irrigação e consequentemente mantém o solo com umidade elevada.

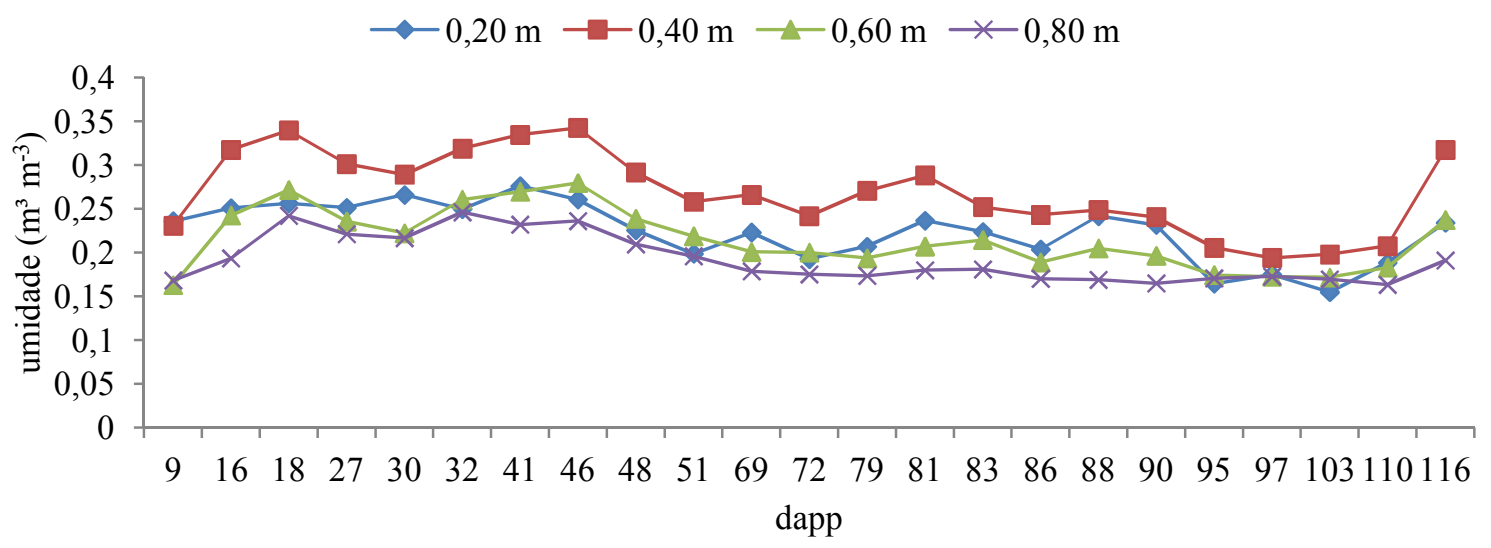

Figura 1. Umidade do solo durante o ciclo produtivo da videira 'Syrah'em Petrolina-PE.

Na Figura 2 são mostradas as concentrações de potássio na solução do solo nas diferentes dosagens estudadas. A $0,40 \mathrm{~m}$ de profundidade (A) praticamente não ocorre aumento da concentração de $\mathrm{K}$ na solução do solo, em relação ao tratamento testemunha para as menores dosagens de $\mathrm{K}$, de 20 e $40 \mathrm{~kg} \mathrm{ha}^{-1}$ de $\mathrm{K}_{2} \mathrm{O}$, com ligueiro decréscimo nas concentração de $\mathrm{K}$ ao longo do ciclo de produção da videira para estes tratamentos. Em um estudo realizado durante 15 semanas, Moraes \& Dynia (1990) observaram que, a 0,20 m de profundidade, as concentrações de $\mathrm{Ca}, \mathrm{Mg}, \mathrm{K}$ e $\mathrm{N}_{-} \mathrm{NO}_{3}$ diminuíram rapidamente a partir da quarta semana, atingindo valores muito baixos. Simultaneamente, as concentrações desses nutrientes aumentaram nas profundidades de 0,40 e $0,60 \mathrm{~m}$, o que demonstra a sua lixiviação. Souza et al. (2012), por outro lado, não observaram perdas de nutrientes por lixiviação na solução do solo na média das variáveis analisadas (amônio, nitrato, P e K) durante 11 meses de amostragem, em ensaios realizados em pomares de laranjeira. 

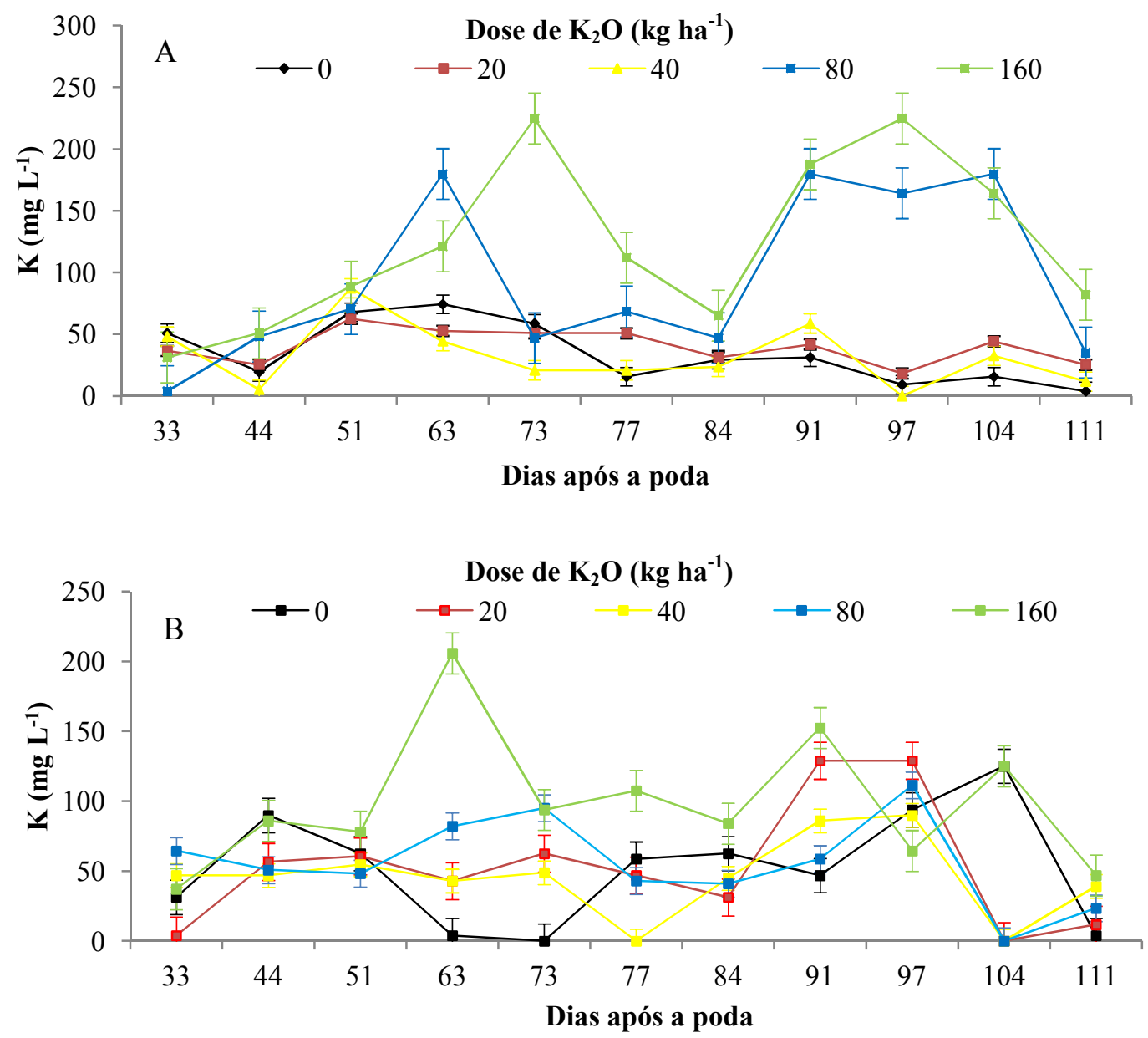

Figura 2. Distribuição de potássio na solução do solo nas profundidades $0,40 \mathrm{~m}$ (A) e $0,60 \mathrm{~m}$ (B) ao longo do ciclo produtivo da videira 'Syrah' em Petrolina-PE.

Observa-se um aumento progressivo da concentração de $\mathrm{K}$ dos 44 aos 73 dias após a poda (dapp) na profundidade $0,40 \mathrm{~m}$ (Figura 2A) para as dosagens 80 e $160 \mathrm{~kg} \mathrm{ha}^{-1} \mathrm{de} \mathrm{K}_{2} \mathrm{O}$ e de 33 a 63 dapp na profundidade $0,60 \mathrm{~m}$ (Figura 2B) para todas as dosagens de $\mathrm{K}_{2} \mathrm{O}$, com exceção de testemunha. Entretanto, nesta mesma profundidade, a concentração de $\mathrm{K}$ na solução é reduzida a partir de 97 dapp em todos os tratamentos. Segundo Terra (2003) a necessidade de K na videira é mais intensa nos estádios de lignificação dos ramos e maturação dos frutos. Considerando as funções fisiológicas do potássio, processos como a transpiração são intensificados nesta fase de desenvolvimento da planta, que requer um controle mais eficiente do uso da água, por meio da abertura e fechameno dos estômatos (TAIZ \& ZIEGER, 2009).

Apesar do ganho no número de cachos $(+2,76 \%)$, na produção total por planta $(+2,5 \%)$ e no rendimento total $(+2,5 \%)$ com a aplicação de $7,5 \mathrm{~m}^{3} \mathrm{ha}^{-1}$ de adubo orgânico no solo, não foi observado efeito nas características avaliadas (Tabela 3). Esta área experimental apresenta resíduos de adubação orgânica de um experimento anterior, realizado com o objetivo de avaliar doses de adubo orgânico e de nitrogênio, e por isso a adubação orgânica do experimento atual foi realizada nas mesmas parcelas que a receberam no experimento anterior; no entanto, a adubação orgânica não afetou as características avaliadas neste primeiro ciclo do experimento com doses de adubo orgânico e de potássio.

A adição de composto orgânico em vinhedos pode alterar as quantidades de nutrientes disponíveis no solo, refletindo no estado nutricional da planta. Como o estado nutricional da 
planta influencia a produção e a composição dos frutos, o composto orgânico não deve ser usado em quantidades que possam afetar negativamente os componentes de produção, como o peso e tamanho dos cachos, o rendimento total, assim com as características de qualidade e composição da uva e do mosto. Embora não tenham ocorrido efeitos sobre as características avaliadas neste primeiro ciclo do experimento com doses de adubo orgânico e de potássio, o composto orgânico pode ter contribuído com a melhoria nos atributos físicos, químicos e biológicos do solo. Ao final do segundo ciclo de produção do experimento com doses de adubo orgânico e de nitrogênio em videiras 'Syrah', Silva et al. (2011) concluíram que a aplicação de adubo orgânico ao solo aumentou os valores de $\mathrm{MO}, \mathrm{pH}, \mathrm{CE}, \mathrm{P}, \mathrm{K}, \mathrm{Ca}, \mathrm{Mg}, \mathrm{Sb}$, CTC e V, mas não exerceu efeitos sobre as características de produção da videira. Depois do terceiro ciclo produtivo foram coletadas amostras de solo na área experimental e os valores de $\mathrm{pH}$ e $\mathrm{CE}\left(\mathrm{dS} \mathrm{m}^{-1}\right)$, assim como os teores de $\mathrm{P}\left(\mathrm{mg} \mathrm{dm}^{-3}\right)$, matéria orgânica $\left(\mathrm{g} \mathrm{dm}^{-3}\right)$ e da CTC $\left(\mathrm{mmol}_{\mathrm{c}} \mathrm{dm}^{-3}\right)$ na camada de 0 a $0,20 \mathrm{~m}$ de profundidade, foram significativamente maiores nas parcelas que receberam adubação orgânica: pH 7,3, CE 0,58, P 107, MO 17,0 e CTC 61,0. Nas parcelas que não receberam adubação orgânica esses valores foram: pH 6,9, CE 0,28, P 48, MO 6,4 e CTC 37,0.

Tabela 3. Resultados do teste $\mathrm{F}$ e da análise de regressão das variáveis número de cachos (NC), produção total por planta (PTP), peso médio dos cachos (PMC) e rendimento total (RT) em função de doses de adubo orgânico e potássico aplicadas em videiras ‘Syrah' em Petrolina-PE no período de 29/04 a 23/08/13

\begin{tabular}{|c|c|c|c|c|}
\hline Tratamento & $\mathrm{NC}$ & PTP & PMC & RT \\
\hline \multicolumn{5}{|l|}{$\mathrm{m}^{3} \mathrm{ha}^{-1}$} \\
\hline \multicolumn{5}{|c|}{$\begin{array}{l}\text {--------g } \text { planta }^{-1} \text {-------- } \\
\text { Adubo Orgânico }^{(1)}\end{array}$} \\
\hline 0 & $8,68 \mathrm{a}$ & $1224,51 \mathrm{a}$ & $143,25 \mathrm{a}$ & $4081,72 a$ \\
\hline 7,5 & $8,92 \mathrm{a}$ & $1255,11 \mathrm{a}$ & $143,38 \mathrm{a}$ & $4183,76 \mathrm{a}$ \\
\hline \multirow{2}{*}{\multicolumn{5}{|c|}{$\begin{array}{c}\text { Adubo Potássico } \\
0 \mathrm{~m}^{3} \mathrm{ha}^{-1} \mathrm{de} \text { adubo orgânico }\end{array}$}} \\
\hline & & & & \\
\hline \multicolumn{5}{|l|}{$\mathrm{kg} \mathrm{ha}^{-1}$} \\
\hline 0 & 8,92 & 1274,00 & 142,87 & 4246,67 \\
\hline 20 & 8,58 & 1282,80 & 147,56 & 4276,00 \\
\hline 40 & 9,44 & 1131,96 & 127,13 & 3773,20 \\
\hline 80 & 7,75 & 1225,73 & 160,81 & 4085,78 \\
\hline 160 & 8,72 & 1208,08 & 137,90 & 4026,93 \\
\hline Regressão & $\mathrm{Q}^{\mathrm{ns}}$ & $\mathrm{L}^{\mathrm{ns}}$ & $\mathrm{Q}^{\mathrm{ns}}$ & $\mathrm{Q}^{\mathrm{ns}}$ \\
\hline $\mathrm{R}^{2}$ & $0,23^{\mathrm{ns}}$ & $0,11^{\mathrm{ns}}$ & $0,11^{\mathrm{ns}}$ & $0,30^{\mathrm{ns}}$ \\
\hline \multicolumn{5}{|c|}{$7,5 \mathrm{~m}^{3} \mathrm{ha}^{-1}$ de adubo orgânico } \\
\hline $\mathrm{kg} \mathrm{ha}^{-1}$ & & & & \\
\hline 0 & 8,54 & 1186,34 & 140,95 & 3954,47 \\
\hline 20 & 9,32 & 1277,60 & 139,84 & 4258,65 \\
\hline 40 & 9,18 & 1294,70 & 142,25 & 4315,67 \\
\hline 80 & 9,32 & 1235,56 & 134,07 & 4118,53 \\
\hline 160 & 8,28 & 1281,36 & 159,81 & 4271,21 \\
\hline Regressão & $\mathrm{Q}^{\mathrm{ns}}$ & $\mathrm{L}^{\mathrm{ns}}$ & $\mathrm{Q}^{\mathrm{ns}}$ & $\mathrm{Q}^{\mathrm{ns}}$ \\
\hline $\mathrm{R}^{2}$ & $0,87^{\mathrm{ns}}$ & $0,11^{\mathrm{ns}}$ & $0,87^{\mathrm{ns}}$ & $0,26^{\mathrm{ns}}$ \\
\hline
\end{tabular}

(1) Médias seguidas de letras iguais na coluna não diferem entre si pelo teste $\mathrm{F}$ a $5 \%$ de probabilidade para as doses de adubo orgânico estudadas. ${ }^{(2) \text { ns: }}$ não significativo; L: linear e Q: quadrática. 
A resposta a adubação orgânica em espécies frutíferas perenes ou semiperenes muitas vezes não ocorre imediatamente no primeiro ciclo de produção, considerando as características de cada espécie, mas pode ocorrer ao longo dos ciclos de produção. Dados obtidos em cinco ciclos produtivos de bananeira-'Prata-anã' em Botucatu-SP, com cinco doses de composto orgânico $(0,43,86,129$ e $172 \mathrm{~kg}$ por planta) mostraram que, apenas no quinto ano de produção houve aumento da massa de cachos, obtido com as duas maiores quantidades de compostos aplicadas, o que, economicamente, indica a aplicação de $129 \mathrm{~kg}$ de composto por planta, correspondendo a aplicação de $468,8 \mathrm{~kg} \mathrm{de}_{2} \mathrm{O}$ ha $^{-1}$ ano $^{-1}$ (DOMATTO JUNIOR et al., 2011). Em mangueiras 'Tommy Atkins'adultas, cultivadas em sistema orgânico irrigado no semiárido brasileiro, Silva et al. (2013) concluíram que a produção e o número de frutos por planta foram maiores com adubos orgânicos provenientes de compostos enriquecidos com MB4 ${ }^{\circledR}$ e termofosfato, que apresentaram maiores concentrações totais de nutrientes. Em um trabalho conduzido durante 8 anos no Vale do Po, na Itália, realizado com nectarineiras 'Stark RedGold', os rendimentos em produção aumentaram de 13,5 t ha ${ }^{-1}$ para 19,9 t ha ${ }^{-1}$ em função do aumento de doses de adubo orgânico, da matéria orgânica do solo e da maior disponibilidade de nutrientes N, P e K no solo (BALDI et al., 2010; TOSELLI, 2010). Por outro lado, em nectarineiras 'Orion'cultivadas em potes por dois anos, Bravo et al. (2012) relatam que a aplicação de adubo orgânico na forma de composto, constituído por material de poda de árvores urbanas e resíduos orgânicos domésticos, aumentou a fixação de ${ }^{13} \mathrm{CO}_{2}$, promovendo o crescimento da parte aérea e raízes das nectarineiras, mas não afetou a biomassa dos frutos nem a absorção de nitrogênio. Assim, é possível que a resposta das videiras 'Syrah' a adubação orgânica possa ocorrer após alguns ciclos de produção.

No ciclo de produção atual, não foram observados aumentos de produtividade, nem das características de produção avaliadas em função das doses crescentes de potássio, aplicadas via fertirrigação (Tabela 3). Contudo, como pode ser observado na Figura 2, houve aumento das concentrações de potássio na solução solo em função do aumento das doses de fertilizantes potássicos. Entretanto, nos períodos de maior demanda pela videira a concentração de potássio presente na solução do solo foi reduzida. Souza et al. (2012) também obtiveram aumento dos teores de $\mathrm{N}_{-} \mathrm{NH}_{4}, \mathrm{~N}_{-} \mathrm{NO}_{3}, \mathrm{P}$ e K na solução do solo com o aumento das doses aplicadas dos fertilizantes, tanto a 0,30 quanto 0,60 $\mathrm{m}$ de profundidade. Em ambos os trabalhos não foram observadas perdas de nutrientes por lixiviação na solução do solo. Estes autores observaram ainda que houve aumento de produtividade ao final do experimento com dois cultivares de laranjeira, com ajuste quadrático às doses de $\mathrm{N}, \mathrm{P}$ e $\mathrm{K}$ aplicadas via fertirrigação, independentemente da variedade estudada. Nas funções ajustadas, os valores máximos de produção foram de 39 e $33 \mathrm{t} \mathrm{ha}^{-1}$, que corresponderam, respectivamente, a 135\% (doses de 189, 54 e $176 \mathrm{~kg} \mathrm{ha}^{-1}$ ) e $138 \%$ (doses de 193,55 e $179 \mathrm{~kg}$ $\mathrm{ha}^{-1}$ ) das doses de N, P e K recomendadas, para as laranjeiras 'Valência' e 'Hamlin'. Assim, é possível que o comportamento do potássio na solução do solo se modifique ao longo dos ciclos de produção da videira, assim como a sua absorção pela planta e seus efeitos na produtividade e nas características de produção.

\section{CONCLUSÕES}

O uso de extratores de cápsulas porosas permitiu o monitoramento da concentração de potássio disponivel para as plantas na solução do solo. No primeiro ciclo de produção avaliado, após o uso de diferentes doses de fertilizantes, não foram observados efeitos do adubo orgânico no rendimento, nem das características de produção avaliadas. As diferentes doses de potássio aplicadas via fertirrigação também não influenciaram na produtividade das plantas. 


\section{REFERÊNCIAS BIBLIOGRÁFICAS}

ALBUQUERQUE, T. C. S. de; ALBUQUERQUE NETO, A. A. R. de; DEON, M. D. Exportação de nutrientes pelas videiras cvs. Itália e Benitaka cultivadas no Vale do São Francisco. In: CONGRESSO BRASILEIRO DE FISIOLOGIA VEGETAL, 10.; CONGRESSO LATINO AMERICANO DE FISIOLOGIA VEGETAL, 12., 2005, Recife. Anais... Recife: SBFV, 2005. CD-ROM.

ALLEN, R.G.; PEREIRA, L.S.; PAES, D.; SMITH, M. Crop evapotranspiration: guidelines for computing crop water requirements. Roma: FAO, 1998, 328p. (Irrigation and Drainage Paper, 56).

BALDI, E., TOSELLI, M., MARCOLINI, G., QUARTIERI, M., CIRILLO, E., INNOCENTI, A.; MARANGONI, B. Compost can successfully replace mineral fertilizers in the nutrient management of commercial peach orchard. Soil Use and Management, Oxford, v.26, n.3, p.346-353, 2010.

BASSOI, L. H.; DANTAS, B. F.; LIMA FILHO, J. M. P.; LIMA, M. A. C.; LEÃO, P. C.S.; SILVA, D. J.; MAIA, J. T. L.; SOUZA, C. R. Preliminary results of a long -term experiment about RDI and PRD irrigation strategies in winegrapes in São Francisco Valley, Brazil. Acta Horticulturae, The Hague, v.754, p.275-282, 2007.

BORGES, A. L.; SILVA, D. J. Fertilizantes para fertirrigação. In: SOUSA, V. F. de; MAROUElli, W. A.; COELHO, E. F.; PINTO, J. M.; COELHO FILHO, M. A. (Ed.). (Ed.). Irrigação e fertirrigação em fruteiras e hortaliças. Brasília, DF: Embrapa Informação Tecnológica, 2011. cap.7, p.253-264.

BRAVO, K.; TOSELLI, M.; BALDI, E.; MARCOLINI, G.; SORRENTI, G; QUARTIERI, M.; MARANGONI, B. Effect of organic fertilization on carbon assimilation and partitioning in bearing nectarine trees. Scientia Horticulturae, Amsterdan, v.137, p.100-106, 2012.

BUSTAMANTE, M.A.; SAID-PULLICINO, D. AGULLÓ, E. AUDREU, J. PAREDES, C. Application of winery and distillery waste composts to a Jumilla (SE Spain) vineyard: Effects on the characteristics of a calcareous sandy-loam soil. Agriculture Ecosystem and Environment, Amsterdan, v.140, p.80-87, 2011.

CUNHA, T. J. F.; PETRERE, V. G.; SILVA, D. J.; MENDES, A. M. S.; MELO, R. F. de; OLIVEIRA NETO, M. B. de; SILVA, M. S. L. da; ALVAREZ, I. A. Principais solos do semiárido tropical brasileiro: caracterização, potencialidades, limitações, fertilidade e manejo. In: SA, I. B.; SILVA, P. C. G. da. Semiárido brasileiro: pesquisa, desenvolvimento e inovação. Petrolina: Embrapa Semiárido, 2010. p. 50-87.

DAMATTO JUNIOR, E.R.; BÔAS, R.L.V.; LEONEL, S.; NOMURA, E.S.; FUZITANI, E.J. Crescimento e produção de bananeira Prata-anã adubada com composto orgânico durante cinco safras. Revista Brasileira de Fruticultura, Jaboticabal, v.especial, p.713-721, 2011.

DOURADO NETO, D.; VAN LIER, Q. J. Estimativa de armazenamento de água no solo para a realização do balanço hídrico. Revista Brasileira de Ciência do Solo, Campinas, v.17, n.1, p.9-15, 1993. 
FOGAÇA, A.O.; DAUDT, C.E.; DORNELES, D. Potássio em uvas II. Análise peciolar e sua correlaçãocom o teor de potássio em uvas viníferas. Ciência e Tecnologia de Alimentos, Campinas, v.27, n.3, p.597-601, 2007.

INSTITUTO DO VINHO DO VALE DO SÃO FRANCISCO. Notas técnicas. Disponível em $<$ http://www.vinhovasf.com.br/site/internas/valetecnico.php $>$. Acesso em 30 de março de 2008.

HAWKESFORD, M.; HORST, W.; KICHEY, T.; SCHJOERRING, J.; MOLLER, I.S.; WHITE, P. Functions of macronutrients. In: MARSCHNER, P. (Ed.). Mineral nutrition of higher plants. $3^{\text {th }}$ ed., New York: Elsevier, 2012. p.135-189.

MORAES, J.F.V.; DYNIA, J.F. Uso de cápsulas porosas para extrair solução do solo. Pesquisa Agropecuária Brasileira, Brasília, v.25, p.1523-1528, 1990.

PIRES, R. C. M.; SAKAI, E.; BASSOI, L. H.; FUJIRAMA, M. Irrigação. In: POMMER, C. V. (Ed.). Uva: tecnologia de produção, pós-colheita, mercado. Porto Alegre: Cinco Continentes, 2003. p.477-524.

PEYNAUD, E. Connaissance et travail du vin. Paris: Dunod, 1997. $341 \mathrm{p}$

REYNIER, A. Manuel de viticulture. 10a Edition, Paris: Lavoisier, 2007. 532 p.

SILVA, D. J.; BASSOI, L. H.; ROCHA, M. G.; SILVA, J. A.; SANTOS, A. R. L. Características do solo e de rendimento de videiras Syrah submetidas à adubação orgânica e fertirrigação nitrogenada. $2^{\circ}$ Ciclo de produção. In: CONGRESSO BRASILEIRO DE CIÊNCIA DO SOLO, 33., 2011, Uberlândia. Solos nos biomas brasileiros: sustentabilidade e mudanças climáticas: anais. Uberlândia: SBCS: UFU, ICIAG, 2011. CD-ROM.

SILVA, D. J.; MOUCO, M. A. do C.; GAVA, C. A. T.; GIONGO, V.; PINTO, J. M. Composto orgânico em mangueiras (Mangifera indica L.) cultivadas no Semiárido do Nordeste brasileiro. Revista Brasileira de Fruticultura, Jaboticabal, v.35, n.3, p.875-882, 2013.

SILVA, D. J.; SOARES, J. M. Fertirrigação In: SOARES, J. M.; LEAO, P. C. de S. (Ed.). A vitivinicultura no Semiárido brasileiro. Brasília, DF: Embrapa Informação Tecnológica; Petrolina: Embrapa Semi-Árido, 2009. cap. 11, p.483-512.

SILVA, J. A. M. Irrigação lateralmente alternada e com deficit hídrico na videira cv. Petite Syrah. 2005. 99 f. Dissertação (Mestrado em Engenharia Agrícola) - Universidade Federal de Viçosa, Viçosa, 2005.

SOUZA, T.R.; VILLAS BÔAS, R.L.; QUAGGIO, J.A.; SALOMÃO, L.C.; FORATTO, L.C. Dinâmica de nutrientes na solução do solo em pomar fertirrigado de citros. Pesquisa Agropecuária Brasileira, Brasília, v.47, n.6, p.846-854, 2012.

TAIZ, L.; ZEIGER, E. Fisiologia vegetal. 4.ed. Porto Alegre: Artmed, 2009. 819p. 
TECCHIO, M.A.; MOURA, M.F.; PAIOLI-PIRES, E.J.; TERRA, M.M.; TEIXEIRA, L.A.J.; SMARSI, R.C. Teores foliares de nutrientes, índice relativo de clorofila e teores de nitrato e de potássio na seiva do pecíolo na videira 'Niagara Rosada'. Revista Brasileira de Fruticultura, Jaboticabal, v. 33, n.2, p.649-659, 2011.

TECCHIO, M.A.; PAIOLI-PIRES, E.J.; TERRA, M.M.; GRASSI FILHO, H.; CORREAA, J.C.; VIEIRA, C.R.Y.I. Correlação entre a produtividade e os resultados de análise foliar e de solo em vinhedos de niagara rosada. Ciência Agrotecnica, Lavras, v.30, n.6, p.1056-1064, 2006.

TERRA, M. M. Nutrição, calagem e adubação. In: POMMER, C. V. (Ed.). Uva: tecnologia de produção, pós-colheita, mercado. Porto Alegre: Cinco Continentes, 2003. p.405-476.

TOSELLI, M. Nutritional implications of organic management in fruit tree production. Acta Horticulturae, The Hague, v.868, p.41-48, 2010.

VAN GENUCHTEN, M. T. A closed-from equation for predicting the hydraulic conductivity of unsatured soil. Soil Science American Journal, Haiston, v.44, n.1, p.898-982, 1980. 